\title{
BMJ Open Women with physical disability in pregnancy resident education: a national survey as a needs assessment for curriculum improvement in obstetrics and gynaecology in Canada
}

\author{
Gharid Nourallah Bekdache, ${ }^{1}$ Anne Berndl ${ }^{2}$
}

To cite: Bekdache GN, Berndl A. Women with physical disability in pregnancy resident education: a national survey as a needs assessment for curriculum improvement in obstetrics and gynaecology in Canada. BMJ Open 2019;9:e024505. doi:10.1136/ bmjopen-2018-024505

- Prepublicaton history and additional material is published online only. To view please visit the journal online (http://dx.doi. org/10.1136/bmjopen-2018024505).

Received 29 May 2018 Revised 29 May 2019 Accepted 30 May 2019
Check for updates

(c) Author(s) (or their employer(s)) 2019. Re-use permitted under CC BY-NC. No commercial re-use. See rights and permissions. Published by BMJ.

${ }^{1}$ Maternal Fetal Medicine Division, Mount Sinai Hospital, Toronto, Ontario, Canada

${ }^{2}$ Obstetric and Gynecology, Sunnybrook Health Sciences Centre, Toronto, Ontario, Canada

Correspondence to Gharid Nourallah Bekdache; gbekdache@gmail.com

\section{ABSTRACT}

Objectives To explore the current status to which Canadian obstetrics and gynaecology (Ob-Gyn) programmes teach residents about pregnancy in patients with physical disabilities, and to assess the level of interested in providing formal education sessions in this field. This study also assesses the residents' perception of their knowledge and their comfort level caring for women with physical disabilities (WWPD), which will further determine the need for incorporation of this topic into the residency curriculum.

Design Cross-sectional survey.

Setting All Canadian English accredited Ob-Gyn residency programmes.

Participants Programme directors and residents. Main outcome measures The current self-reported education and exposure Canadian Ob-Gyn residents have surrounding WWPD in pregnancy, and if there is an interest in further education in this area.

Methods An online survey was developed and distributed to all Canadian English accredited Ob-Gyn residency programme directors and residents. Answers were collected over a 2-month period in 2017, which consisted of an initial email and two email reminders. Questions were in three key areas: demographic characteristics, knowledge gap and level of interest in a formal method of education.

Results Eighty-four residents and nine programme directors participated in the surveys. Eighty-six per cent of residents and all programme directors responded that there are no formal scheduled training sessions on WWPD as part of the residency curriculum. Two-thirds of the residents reported being uncomfortable with the management issues surrounding a woman with a disability in pregnancy. A vast majority of residents (91.67\%) and all programme directors have an interest in incorporating this topic into the residency curriculum to meet the need of pregnant women with disabilities.

Conclusions This survey indicated that there is both a need for and interest in education in the area of pregnancy and physical disability in the Canadian Ob-Gyn residency programme. This information suggests that the development of educational materials in this area should be considered to address an unmet need with the ultimate goal of improving the care provided to WWPD in
Strengths and limitations of this study

- To the best of our knowledge, this is the first national survey addressing programme directors and residents in Canada regarding the need for a structured and standardised curriculum for physical disabilities in pregnancy.

- This survey was distributed to Anglophone residency training programmes only as it was not translated to French. Therefore, it is possible that this sample is not representative of all Canadian obstetrics and gynaecology residents and programme directors.

- Although both surveys had respondents from a wide geographical area within Canada, there were disproportionately more responding residents from Ontario. This factor may have skewed the results.

pregnancy. Future projects in this area should focus on content development taking into account the CanMEDS and competency-based medical education framework.

\section{INTRODUCTION}

More than $11 \%$ of Canadian adults experience disability, with women having a higher prevalence of disability compared with men in almost every age group. ${ }^{1}$ Disability is defined as a consequence of impairments, activity limitations, participation restrictions and environmental factors. ${ }^{2}$ More recently, an increased number of women with disabilities want to become pregnant. ${ }^{3-8}$ It is, therefore, essential that adequate medical care is provided to these women throughout their pregnancy. However, numerous studies have shown that healthcare professionals are not properly trained to treat women with physical disabilities (WWPD). ${ }^{4-12}$ For instance, medical professionals are unfamiliar with the needs of women with disabilities and the medical services that they provide are not adequately tailored to these women. ${ }^{3} 91113$ 
Additionally, many physicians lack confidence in treating women with disabilities. ${ }^{14}$ These factors contribute to negative clinical encounters, causing women with disabilities to be less likely to seek out necessary care from an obstetrics and gynaecology (Ob-Gyn) during the prenatal and postnatal periods. ${ }^{15}$ Suboptimal health-seeking behaviour is a serious concern as WWPD are at a higher risk for Caesarean section and adverse pregnancy outcomes such as early labour, preterm birth, pre-eclampsia, autonomic dysreflexia and offspring with low birthweight. ${ }^{6}{ }^{13}$ Lack of knowledge about pregnancy in WWPD is likely related in part to lack of attention to disability in the education and training programmes for clinicians putting pregnant WWPD at higher risk for complications of pregnancy. ${ }^{11}$ The Royal College of Physicians and Surgeons of Canada's 2015 CanMEDS Physician Competency Framework, which defines the foundation for medical education in Canada, states that physicians have a duty to address the needs of a vulnerable population, identify gaps in care delivery and seek opportunities to improve quality and promote patient safety. ${ }^{16}$ Formal educational opportunities in Ob-Gyn residency programmes may address this unmet need, and improve the care provided to women with disabilities throughout their pregnancy. Formal education is defined as scheduled lectures, seminars and simulation sessions. Informal learning is defined as that which occurred outside of structured didactics and learning.

To our knowledge, this is the first survey addressing programme directors and residents in Canada regarding the need for a structured and standardised curriculum for physical disabilities in pregnancy.

The objective of this study is to evaluate the current state to which Canadian Ob-Gyn programmes teach residents about pregnancy in patients with physical disabilities and to determine if there is a perceived need for a formalised educational programme in this field.

\section{METHODS}

We developed an anonymous cross-sectional online survey for residents and programme directors. The survey tools were created based on a review of the literature in response to a series of interviews with WWPD who had recently had a pregnancy and leaders in the disability community. These interviews had been undertaken as a critical patient-engagement step in the development of an antenatal clinic for WWPD. The surveys were distributed and collected using the electronic online survey tool Survey Monkey (Survey Monkey, Palo Alto, California, USA). Surveys were distributed to all accredited Anglophone Ob-Gyn residency programmes in Canada, as this project did not have funding available for translation into French. A letter of request was emailed to programme directors and their administrative assistants of the 13 Anglophone Ob-Gyn residency programmes in Canada for participation. An introductory letter described the rationale and objective of the study, followed by request for informed consent. Programme directors were asked to (1) complete the survey themselves (Programme directors' Survey) and (2) distribute the resident version of the survey to their residents to avoid direct contact between the authors and the residents. The survey was available in English. Informed consent was assumed if the respondent chose to complete the questionnaire. We assumed that the survey had indeed been distributed to residents if (1) the programme director responded to our email to indicate they had distributed or (2) we received responses from residents at that programme.

The programme directors survey asked basic demographic information if there is an inclusion of the topic of women with disability in pregnancy in the curriculum, and if it was included in a specific format, for example, grand rounds or journal club. They were then asked if there was a readily available education session on pregnancy and disability, the degree of interest they would have in incorporating it into the resident's curriculum, on a spectrum of not interested to extremely interested (online supplementary file).

The residents' survey consisted of nine multiple-choice questions (online supplementary file). The resident questionnaire asked about (1) basic demographic data, (2) formal education of the care of pregnant WWPD in residency, (3) resident's knowledge and comfort level with treating WWPD in pregnancy, (4) Interest in incorporating educational sessions such an academic half-day on pregnancy and disability into their curriculum. Surveys responses were analysed using descriptive statistics.

\section{Patient and public involvement}

This research question was developed in response to a series of exit interviews from WWPD who had recently had a pregnancy (APOG, Poster \#12, 2016) as well as interviews with leaders in the disability community. These interviews were undertaken as part of the development of Accessible Care Pregnancy Clinic, a clinic caring for WWPD in pregnancy. The study subjects in this project are programme directors and Ob-Gyn residents, as opposed to patients, and programme directors were involved in recruitment as we relied on them to relay the survey to residents, to protect the privacy of resident emails. Following publication, programme directors will receive an email to distribute to the residents in their programmes, thanking them for their participation and summarising the findings of this study.

\section{RESULTS}

\section{Resident survey}

Surveys were distributed to all thirteen Anglophone Canadian Ob-Gyn residency programme directors. We received confirmation of distribution to residents or at eight of these programmes. Therefore, it is assumed that the surveys were distributed to 265 residents based on the calculation of the number of residents at those 


\begin{tabular}{|lll}
\hline Table 1 Residents' demographic & \multicolumn{3}{l}{ characteristics } \\
\hline Age range & Student \# & $\%$ \\
\hline $25-34$ & 80 & 95.24 \\
\hline $35-44$ & 3 & 3.57 \\
\hline $45-54$ & 1 & 1.19 \\
\hline Total & 84 & 100.00 \\
\hline Gender & Student \# & $\%$ \\
\hline Female & 77 & 91.67 \\
\hline Male & 7 & 8.33 \\
\hline Total & 84 & 100.00 \\
\hline Postgraduate level & Student \# & $\%$ \\
\hline 1 & 23 & 27.38 \\
\hline 2 & 18 & 21.43 \\
\hline 3 & 17 & 20.24 \\
\hline 4 & 14 & 16.67 \\
\hline 5 & 12 & 14.29 \\
\hline Total & 84 & 100.00 \\
\hline University & Student \# & $\%$ \\
\hline McMaster University & 20 & 23.81 \\
\hline University of Alberta & 14 & 16.67 \\
\hline University of Toronto & 14 & 16.67 \\
\hline University of Saskatchewan & 12 & 14.29 \\
\hline University of British Columbia & 10 & 11.90 \\
\hline University of Manitoba & 5 & 5.95 \\
\hline Dalhousie University & 5 & 5.95 \\
\hline Memorial University of & 4 & \\
\hline Newfoundland & & 4.76 \\
\hline University of Calgary & 0 & 0.00 \\
\hline Western University & 0 & 0.00 \\
\hline Queen's University & 0 & 0.00 \\
\hline University of Ottawa & 0 & 0.00 \\
\hline Total & 84 & 100.00 \\
\hline & & \\
\hline
\end{tabular}

schools using the information from Canadian Resident Matching Service.

A total of 84 residents' survey were completed and returned. Therefore, the response rate was $84 / 265$ or $32 \%$.

\section{Residents' demographic characteristics}

Demographic features of the 84 respondents are listed in table 1 . Of all resident respondents, $91.67 \%$ were female (77 of 84 ), which is likely representative of the current gender ratio in Ob-Gyn training programmes. The largest number of respondents (20 of $84(23.81 \%)$ ) was from McMaster University. Residents from all postgraduate year levels completed the survey.

\section{Resident experience in physical disabilities in pregnancy}

Most residents responded that they had not received or participated in any formal methods of education on the

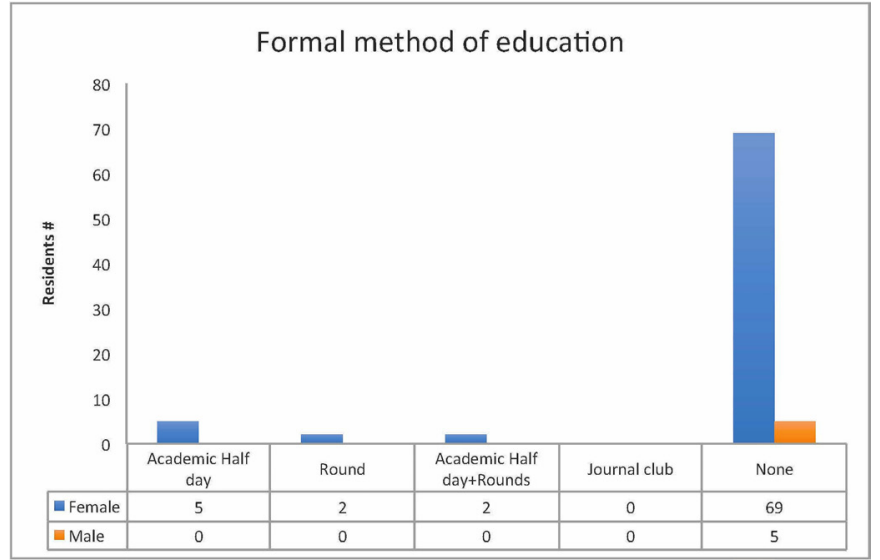

Figure 1 Resident's formal method of education on the topic of WWPD in pregnancy. WWPD, women with physical disabilities.

topic of pregnancy and physical disabilities (figure 1). Minimal informal education, 'the topic was mentioned once or twice' was reported in 40/84, 47.6\% (figure 2). $40.5 \%$ residents $(34 / 84)$ reported having seen a pregnant patient or patient with physical disabilities planning a pregnancy in a clinical capacity at least two to five times. Most residents $(57 / 84,67.86 \%)$ feel uncomfortable with the management issues surrounding a woman with a disability in pregnancy (figure 3 ). A total of $77 / 84(91.67 \%)$ of residents indicate that they are interested in a formal education about pregnancy in WWPD (figures 4 and 5). Among the 77 residents, $72(72 / 77$ $(93.5 \%))$ female and $5(5 / 7(71.4 \%))$ male residents were interested in formal education. The largest number of female residents was in their first year of residency.

\section{Programme director survey}

Nine programme directors completed and returned the survey. Therefore, the response rate was $9 / 13$ or $69 \%$. All programme directors that responded indicated that their programmes did not include formal education or training in women with disability in pregnancy as part of the residency curriculum.

In addition, most programme directors (8/9) confirmed that there were no resident education opportunities for women with disability in pregnancy in the

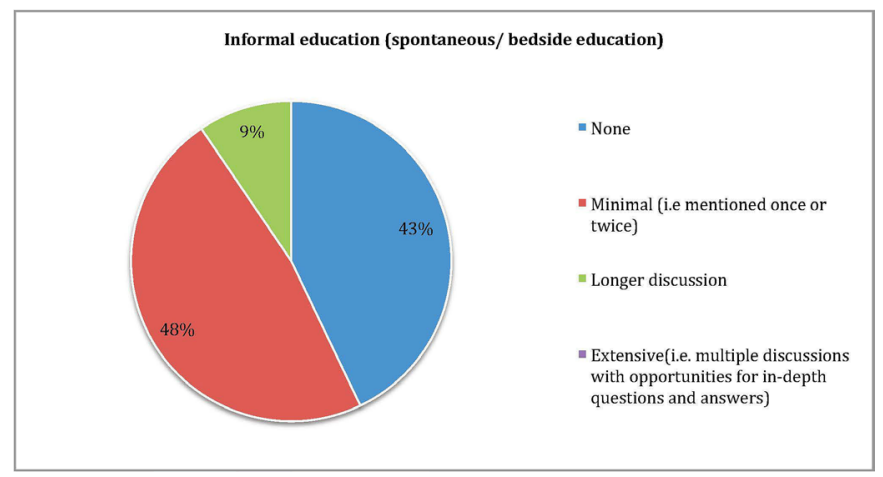

Figure 2 Informal education on the topic of pregnancy and physical disability. 


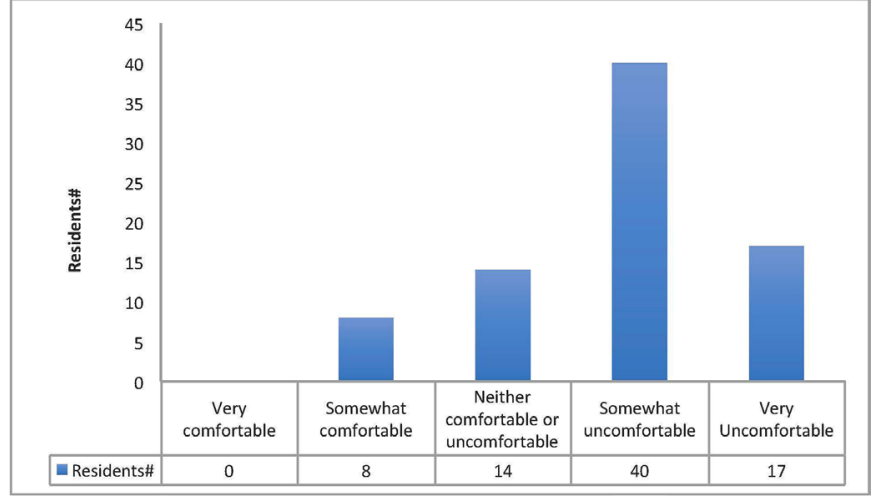

Figure 3 Resident's comfort level with the management of WWPD in pregnancy. WWPD, women with physical disabilities.

past 2 years. Out of nine, eight programme directors are at least moderately interested in incorporating this topic into the resident curriculum, and 6/9 were very/ extremely interested in incorporating this topic into the curriculum (figure 6).

\section{DISCUSSION}

More WWPD are choosing to become pregnant, ${ }^{17}$ and are more likely to have pregnancy-related complications such as preterm birth, low birthweight, Neonatal Intensive Care Unit (NICU) admission and neonatal death. ${ }^{15}$ As well, WWPD are less likely to receive prenatal care in the first trimester, ${ }^{15}$ and are susceptible to complications associated with a physical disability such as falls and respiratory complications. ${ }^{5}$ Compounding this risk, WWPD perceive 'a real lack of information within the Ob-Gyn community'. ${ }^{9}$ Our study demonstrates that current trainees recall minimal educational opportunities in the field of WWPD, although almost half had clinical experience with WWPD.

Furthermore, the majorities of residents express discomfort with caring for WWPD, and perhaps most importantly, are interested in a formal education session on WWPD and pregnancy. It is of interest that women

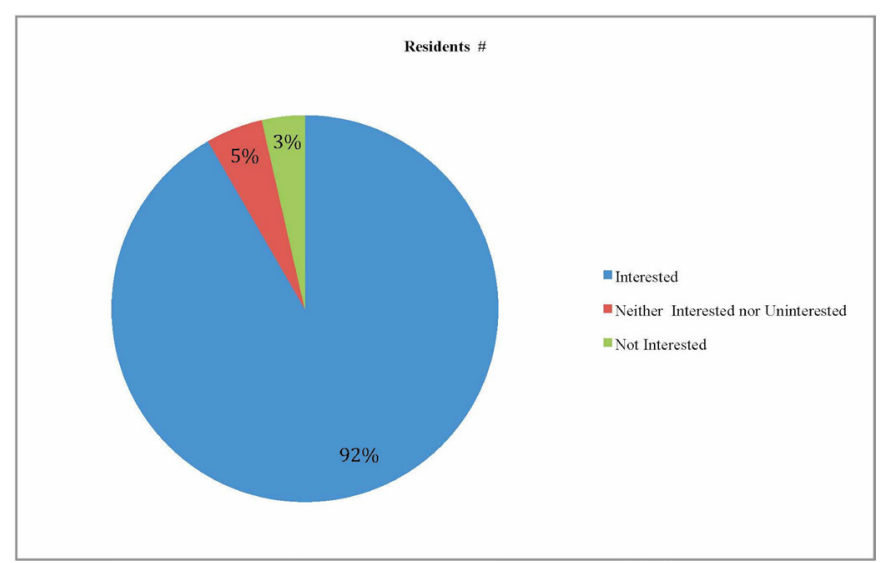

Figure 4 Resident's formal education interest in physical disabilities in pregnancy.

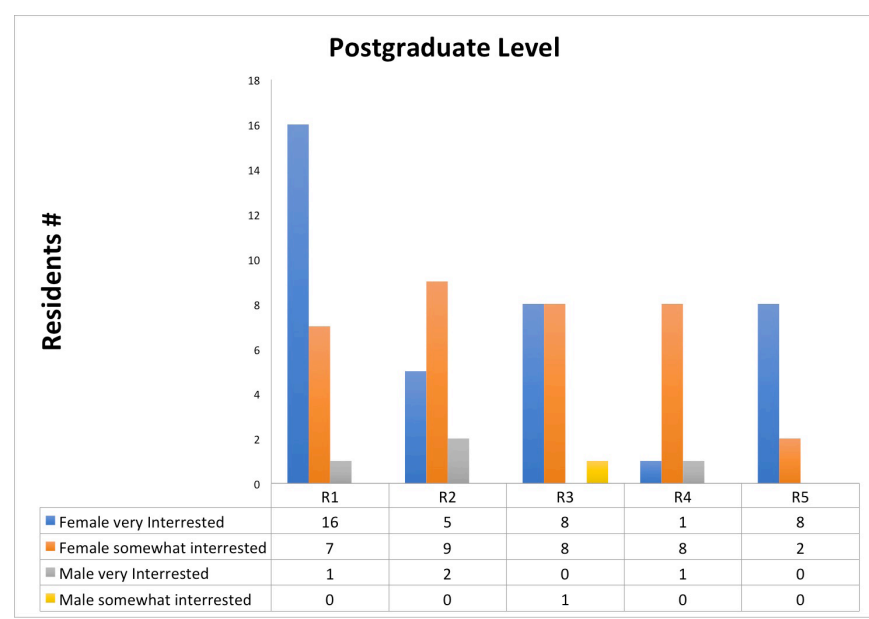

Figure 5 Distribution of interested Residents by training level and gender.

appear more interested in formal education sessions than men. However, the number of men surveyed is small, and therefore, it is not possible to draw conclusions surrounding this observation. The desire for formal education is reflected in the programme directors' survey, with the majority stating there is no formal training offered, however, would be interested in incorporating an educational session into their resident curriculum. This survey confirms a perceived need and desire for resident education in this area.

There is some progress in the area of care for WWPD in pregnancy. Sunnybrook Health Sciences Center established the Accessible Care Pregnancy Clinic, the first specialised clinic to provide obstetrical care for women with disabilities in North America. ${ }^{18}$ The American College of Ob-Gyn developed an interactive online site for clinicians serving women with disabilities discussing common concerns in this community. ${ }^{19}$ The development of an interactive website and a specialised clinic represent meaningful progress on this issue. However, residents should have and have expressed a desire to have formal educational sessions on this topic.

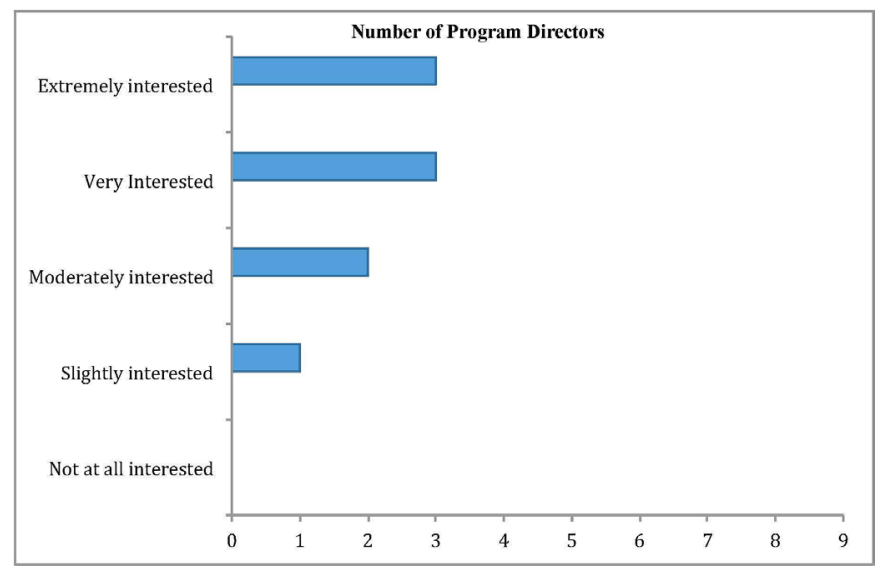

Figure 6 Programme directors' interest level in formal education. 
The needs of WWPD in pregnancy are quite varied and differ depending on the reason for the physical disability. For example, women with spinal cord injuries are at risk for autonomic dysreflexia, ${ }^{13}{ }^{20}$ whereas a woman with cerebral palsy is not. However, both of these women may require the use of a wheelchair accessible scale, be more likely to experience prejudice during their pregnancy ${ }^{1320}$ and be at increased risk of bladder infection. ${ }^{1320}$ A curriculum for women with disabilities in pregnancy fits well into the CanMEDS framework, which is a framework 'for improving patient care by enhancing physician training, ${ }^{21}$ It would provide an opportunity to highlight common obstetrical concerns for WWPD, (medical expert), while also discussing the need for advocacy (health advocate), person-centred care (communicator) and interdisciplinary care (collaborator). Formal education could be in the format of an academic half-day. WWPD should be consulted and central to curriculum development, ideally including examples of their pregnancy experiences in their own words. Formal education could be accomplished through the creation of a video or series of vignettes that could be distributed electronically for academic use.

To our knowledge, this is the first published study to evaluate the current state of education among Canada's postgraduate training programmes in $\mathrm{Ob} / \mathrm{Gyn}$. Our results confirm a suspected gap in resident formal education in pregnancy and physical disability. This study, however, had several limitations. The survey was only distributed to English-speaking schools, as we did not have the funding available to have it translated to French, which resulted in the lack of information from francophone residency programmes. As well, to protect resident privacy, the survey was distributed through the programme directors themselves, who may or may not have resent the reminder emails, which could result in a lower response rate. Data were missed from specific institutions, and it is unknown what the educational experiences are at those sites. Although both surveys had respondents from a wide geographical area within Canada, there were disproportionately more responding residents from Ontario.

This study reports on the current level of education in Canadian postgraduate training programmes in Ob-Gyn in the area of pregnancy and disability and demonstrates a perceived desire from both residents and programme directors to include formal education on this topic. This finding suggests the need for the development of educational materials in this field to ensure that our future practitioners have an adequate set of skills to respond effectively to the needs of disabled women during pregnancy.

\section{CONCLUSION}

This survey provides a contemporary assessment of the current status of education on the topic of physical disability in pregnancy and identifies a deficiency in the formal and informal education. Information gathered from this survey demonstrates a gap in knowledge and provides evidence for the need to develop curricula in this field. We hope that through physician education, WWPD will have access to high-quality, compassionate, evidence-based obstetrical care. Future research efforts should focus on establishing the content of resident educational materials, how we would address competency in this area as part of competency-based medical education and the most appropriate method of distribution. These goals require input from educators, experts and members of the disabled community. This study focuses on obstetrical care for WWPD. Future studies may also examine gynaecological care.

Contributors $A B$ was involved in study conception, survey design and supervision of research. GNB was involved in the development of the online survey, data acquisition, interpretation of the data and drafting the manuscript.

Funding The authors have not declared a specific grant for this research from any funding agency in the public, commercial or not-for-profit sectors.

Competing interests $A B$ : reports grants from Sunnybrook AFP grant and grant from University of Toronto Department of Neurology New Initiatives Program, both grants are outside the submitted work: Sunnybrook AFP grant: Funding for other non-related trial entitled 'High Volume Foleys increasing Vaginal Birth feasibility trial' and University of Toronto Department of Neurology New Initiatives Program: Funding for other non-related study 'A Patient-Oriented study on Pregnancy in Myasthenia Gravis'.

Patient consent for publication Not required.

Ethics approval Residents and programme directors were reviewed and approved by the hospital's Research Ethics Board 036-2017.

Provenance and peer review Not commissioned; externally peer reviewed.

Data sharing statement There are no additional data available.

Open access This is an open access article distributed in accordance with the Creative Commons Attribution Non Commercial (CC BY-NC 4.0) license, which permits others to distribute, remix, adapt, build upon this work non-commercially, and license their derivative works on different terms, provided the original work is properly cited, appropriate credit is given, any changes made indicated, and the use is non-commercial. See: http://creativecommons.org/licenses/by-nc/4.0/.

\section{REFERENCES}

1. Metzler M. Statistics Canada. Table 2: Prevalence of disability by age and sex group, Canada, 2012. In Disability in Canada: Initial findings from the Canadian Survey on Disability. 2013. Retrieved from http:// www.statcan.gc.ca/pub/89-654-x/ 20013002-eng.htm.

2. World Health Organization. InternationalClassification of Functioning, Disability and Health. Geneva: World Health Organization, 2001.

3. Malouf R, Redshaw M, Kurinczuk JJ, et al. Systematic review of heath care interventions to improve outcomes for women with disability and their family during pregnancy, birth and postnatal period. BMC Pregnancy Childbirth 2014;14:58.

4. Malouf R, Henderson J, Redshaw M. Access and quality of maternity care for disabled women during pregnancy, birth and the postnatal period in England: data from a national survey. BMJ Open 2017;7:e016757.

5. lezzoni LI, Wint AJ, Smeltzer SC, et al. Effects of disability on pregnancy experiences among women with impaired mobility. Acta Obstet Gynecol Scand 2015;94(2):133-40.

6. Lawler D, Lalor J, Begley C. Access to Maternity Services for Women With a Physical Disability: A Systematic Review of the Literature. Int J Childbirth 2013;3:203-17.

7. National Institute of Child Health and Human Development, Office of the Director. Pregnancy in women with physical disabilities. 2010. Retrieved from http://www.nichd.nih.gov/news/profiles/KnowNICHD/ signore/Pages/default.aspx.

8. Long-Bellil L, Mitra M, lezzoni LI, et al. The Impact of Physical Disability on Pregnancy and Childbirth. J Womens Health 2017;26:878-85. 
9. Mitra M, Long-Bellil LM, lezzoni LI, et al. Pregnancy among women with physical disabilities: Unmet needs and recommendations on navigating pregnancy. Disabil Health J 2016;9:457-63.

10. Tarasoff LA. Experiences of women with physical disabilities during the perinatal period: a review of the literature and recommendations to improve care. Health Care Women Int 2015;36:88-107.

11. Smeltzer SC, Mitra M, lezzoni LI, et al. Perinatal Experiences of Women With Physical Disabilities and Their Recommendations for Clinicians. J Obstet Gynecol Neonatal Nurs 2016;45(6).

12. Swati C, Padmaja S. Physical disabilities in pregnant women: Impact on care and pregnancy outcome. International Journal of Reproduction, Contraception. Obstet Gynecol 2017;6.

13. Smeltzer SC. Pregnancy in women with physical disabilities. J Obstet Gynecol Neo Nurs 2007;36:88-96.

14. Bertschy S, Geyh S, Pannek J, et al. Perceived needs and experiences with healthcare services of women with spinal cord injury during pregnancy and childbirth - a qualitative content analysis of focus groups and individual interviews. BMC Health Serv Res 2015; $15: 234$

15. Mitra M, Clements KM, Zhang J, et al. Maternal Characteristics, Pregnancy Complications, and Adverse Birth Outcomes Among Women With Disabilities. Med Care 2015;53:1027-32.
16. Wong BS, Ackroyd-Stolarz M, Bukowskyj L, et al. The CanMEDS 2015 Patient Safety and Quality Improvement Expert Working Group Report. Ottawa: Royal College of Physicians and Surgeons of Canada, 2015

17. Horner-Johnson W, Biel FM, Darney BG, et al. Time trends in births and cesarean deliveries among women with disabilities. Disabil Health J 2017:10:376-81.

18. Vuchnich A, Tang V. Specialized clinic provides care for pregnant women with disabilities. 2018. Available at https://globalnews. $\mathrm{ca} /$ news/3447669/specialized-clinic-provides-care-for-pregnantwomen-with-disabilities (accessed 26 Jan 2018).

19. Cox JL, Signore C, Quint E; American College of Obstetricians and Gynecologists. Interactive site for clinicians serving women with disabilities. In American College of Obstetricians and Gynecologists: Women with disabil- ities. 2012. Retrieved from http://www.acog.org/ About_ACOG/ACOG_Departments/ Women with Disabilities.

20. American College of Obstetricians and Gynecologists. Obstetric management of patients with spinal cord injuries (ACOG Committee Opinion no. 275). Obstet Gynecol 2002;100:625-7.

21. Frank JR, ed. The CanMEDS 2005 physician competency framework. Better standards. Better physicians. Better care. Ottawa: The Royal College of Physicians and Surgeons of Canada, 2005. 